\title{
EFFICACY OF LOTION CONTAINING FRACTIONS OF SELAGINELLA PLANA LEAVES AND LAGENARIA SICERARIA (MOLINA) STANDL. FRUIT FOR RELIEF OF SKIN ERYTHEMA
}

\author{
FEBRIYANTI WULANDARI ${ }^{1}$, JOSHITA DJAJADISASTRA ${ }^{2}$, BERNA ELYA ${ }^{3 *}$ \\ ${ }^{1}$ Herbal Master Program, Faculty of Pharmacy, Universitas Indonesia, Depok, 16424, Indonesia. ${ }^{2}$ Department of Pharmaceutical \\ Technology, Faculty of Pharmacy, Universitas Indonesia, Depok, 16424, Indonesia. ${ }^{3}$ Department of Phytochemical and Pharmacognosy, \\ Faculty of Pharmacy, Universitas Indonesia, Depok, 16424, Indonesia. Email: berna.elya@farmasi.ui.ac.id
}

Received: 15 June 2018, Revised and Accepted: 20 September 2018 and 25 October 2018

ABSTRACT

Objective: The aim of this study is to evaluate the physical stability of two lotion formulations containing Selaginella plana and Lagenaria siceraria (Molina) Standl. and investigated their safety and efficacy to relieve erythema due to exposure to the sun.

Methods: We conducted a randomized controlled trial consisting of five treatment groups: Negative control, positive control, neutral control, formula A test group (containing a $1 \%$ ethanolic fraction of S. plana and a $0.5 \%$ ethanolic fraction of L. siceraria [Molina] Standl.), and formula B test group (containing a $0.5 \%$ ethanolic fraction of S. plana and a $1 \%$ ethanolic fraction of L. siceraria [Molina] Standl.). Each group had erythema induced by exposure to sunlight for $30 \mathrm{~min}$ between 10:00 and 16:00. The severities of erythema 1, 3, and $24 \mathrm{~h}$ after application were assessed.

Results: Formula A was significantly better than formula B $(\mathrm{p}<0.05)$ at reducing the severity of erythema.

Conclusion: Formula A containing a 1\% ethanol fraction of S. plana and a $0.5 \%$ ethanol fraction of L. siceraria (Molina) Standl. showed the greatest reduction in the level of erythema $(\mathrm{p}<0.05)$. S. plana may reduce the prostaglandin synthesis caused by sun exposure.

Keywords: Erythema, Selaginella sp., Lagenaria sp., Flavonoids, Amino acids, Fraction of ethanol, Lotion.

(c) 2018 The Authors. Published by Innovare Academic Sciences Pvt Ltd. This is an open access article under the CC BY license (http://creativecommons. org/licenses/by/4. 0/) DOI: http://dx.doi.org/10.22159/ijap.2018.v10s1.40

\section{INTRODUCTION}

Inflammation is caused by microorganisms, mechanical trauma, chemicals, and the effects of sun exposure. Erythema is one sign of inflammation, and exposure to the sun is the dominant cause in Indonesia, which is a tropical country in which most of the population works outdoors throughout the year. One practical approach to acute sunburn caused by ultraviolet (UV) rays is to treat the symptoms such as erythema (redness), pain (pain), and itching [1-5]. Research and development is active to develop skin care lotions using herbal active ingredients to relieve erythema of the skin due to exposure to the sun $[6,7]$.

In the pathogenesis of erythema, UV light stimulates the release of histamine, kinins, and prostaglandins that cause damage to keratinocytes. The minimal erythema dose (MED) is defined as the minimum amount of radiation that can cause skin erythema and can be observed up to $24 \mathrm{~h}$ after exposure to sunlight [8]. Skin exposed to sunlight will produce erythema quickly or slowly and can cause browning of the skin (tanning) $[9,10]$.

Selaginella plana leaves and Lagenaria siceraria (Molina) Standl. fruit have been shown in previous studies to contain active compounds that are soothing and useful for the treatment of inflammation. However, the proportions of S. plana fractions and L. siceraria (Molina) Standl. fractions have not been standardized and required investigation. In addition, assays of flavonoid and amino acid content should be performed before producing lotion formulations. In this study, we evaluated the physical stability of two lotion formulations containing S. plana and L. siceraria (Molina) Standl. and investigated their safety and efficacy to relieve erythema due to exposure to the sun [11-13].

\section{MATERIALS AND METHODS}

This was an experimental study. First, we prepared fractions of S. plana and L. siceraria (Molina) Standl. in ethanol. Solutions of the extracted fractions were analyzed for organoleptic, moisture content, loss on drying, ash content, water-soluble extract content, and ethanol-soluble extract content. In phytochemical screening, flavonoids in the ethanolic fraction of S. plana and amino acids in the fraction of L. siceraria (Molina) Standl. were assayed. A lotion containing a fraction of S. plana and a fraction of L. siceraria (Molina) Standl. was prepared, characterized by physical evaluation, and tested for stability. The safety and efficacy of the lotion in vivo was evaluated. Ethics approval was obtained from the Faculty of Medicine, University of Indonesia, Number 419/UN2.F1/ ETHICS/2016. The MED was determined in 22 volunteers. MED readings were taken before and immediately after 30-min exposure to $\mathrm{UV}$ radiation from the sun. The lotion was applied in a randomized double-blind manner, and MED readings were taken 1, 3, and $24 \mathrm{~h}$ after the application of the lotion.

\section{Equipment and materials}

The following equipment was used in this study: Analytical balance (Kenko), glass labware, homogenizer (Sower), freeze-dryer (Modulyo), spectrophotometer (UV mini-1240; Shimadzu), centrifuge (Kobuta 5100; Japan), pH Meter (Hanna), Brookfield viscometer (USA), highperformance liquid chromatography (HPLC) (Waters, USA), and a Mexameter $^{\circledR}(\mathrm{CK})$.

The botanical materials were S. plana leaves from Bogor, L. siceraria fruit, and extract Chamomilla recutita (Matricaria).

\section{Procedures}

Preparation of S. plana fraction

Fresh leaves of $S$. plana were sorted, washed, chopped, and dried in an oven at $45^{\circ} \mathrm{C}$. The dried powder was extracted by maceration in $70 \%$ ethanol. $\mathrm{N}$-hexane was added to obtain an $\mathrm{n}$-hexane extract fraction. To ensure the quality of the fraction, the fraction was characterized by 
performing phytochemical screening for alkaloids, flavonoids, saponins, tannins, and triterpenoids/steroids.

\section{Determination of quercetin (a flavonoid) levels in the leaffraction of S. plana}

The determination of flavonoid was performed using a Spectrophotometer UV Vis. $0.5 \mathrm{~mL}$ of standard or sample solutions was added into $1,5 \mathrm{~mL}$ of ethanol followed by $0.1 \mathrm{~mL}$ of $10 \% \mathrm{AlCl}_{3}$. Afterward, $0.1 \mathrm{~mL}$ of $1 \mathrm{M} \mathrm{CH}_{3} \mathrm{COONa}$ and $2.8 \mathrm{~mL}$ of aquadest was added to the mixture. The mixture was kept in a dark room. The absorbance of the standard solution was read at a wavelength of $417 \mathrm{~nm}$. To samples $(0.5 \mathrm{~mL})$ with a concentration of $1000 \mu \mathrm{g} / \mathrm{mL}$ was added to $1.5 \mathrm{~mL}$ of ethanol, $0.1 \mathrm{~mL}$ of $1 \mathrm{M} \mathrm{CH} 3 \mathrm{COONa} \cdot 3 \mathrm{H}_{2} \mathrm{O}$, and $2.8 \mathrm{~mL}$ of aquabidest. The mixture was kept in a dark room for $30 \mathrm{~min}$. A UV-VIS spectrophotometer (UV-1240; Shimadzu) was used to read the absorbance of the solution fraction was read at a wavelength of $417 \mathrm{~nm}$ [14].

\section{Preparation of L. siceraria fraction}

Some of the fresh L. siceraria was extracted by maceration in $96 \%$ ethanol. The next stage was fractionation using ethyl acetate. We performed phytochemical screening of alkaloids, flavonoids, saponins, tannins, triterpenoids/steroids, and amino acids to ensure the quality of the fractions.

Determination of amino acid concentrations in the ethanol fraction of L. siceraria

An HPLC method was used to determine the amino acid concentrations in the ethanol fraction of $L$. siceraria by comparison with a standard solution of amino acids. An HPLC instrument with a type ACCQ Tag Ultra C18 column and a photodiode array detector was used at a UV detection wavelength of $260 \mathrm{~nm}$. A gradient mobile phase system was used at a flow rate of $0.7 \mathrm{~mL} / \mathrm{min}$. The injection volume was $1 \mu \mathrm{L}$.

\section{Lotion formulations}

The lotion was prepared by making an emulsion of oil and water phases with an emulsifier. Two formulas, A and B, were made. Table 1 shows the compositions.

\section{Evaluation of lotion preparations}

The lotion formulas were evaluated for organoleptic including color, odor, and homogeneity; $\mathrm{pH}$, viscosity, and particle size.

\section{Physical stability tests of the lotion test preparations}

The stability of the lotion preparations was tested for odor, color, and $\mathrm{pH}$ and evaluated at temperatures of $40^{\circ} \mathrm{C} \pm 2^{\circ} \mathrm{C} ; 28^{\circ} \mathrm{C} \pm 2^{\circ} \mathrm{C}$, and $40^{\circ} \mathrm{C} \pm 2^{\circ} \mathrm{C}$ for 12 weeks, with observations every 2 weeks.

\section{Table 1: Lotion compositions: Formula A (FA) and Formula} B (FB)

\begin{tabular}{lll}
\hline Compositions & FA (\%) & FB (\%) \\
\hline Selaginella plana & 1 & 0.5 \\
Lagenaria siceraria & 0.5 & 1 \\
Glycerin & 5 & 5 \\
Triethylamine & 0.2 & 0.2 \\
Sodium EDTA & 1 & 1 \\
Propylene glycol & 1 & 1 \\
Methylparaben & 0.18 & 0.18 \\
Aquabidest & 79.9 & 79.9 \\
Stearic acid & 3 & 3 \\
Glyceryl monostearate & 2 & 2 \\
Cetyl alcohol & 2 & 2 \\
Isopropyl myristate & 2 & 2 \\
Paraffin liquid & 2 & 2 \\
Butyl hydroxytoluene & 0.1 & 0.1 \\
Propylparaben & 0.02 & 0.02 \\
\hline
\end{tabular}

\section{Safety test}

Safety tests of the lotion preparations were performed by observing the skin of the subjects and assessing the degree of irritation or allergic reactions $48 \mathrm{~h}$ after lotion application. Possible side effects included redness, swelling, edema, itching, and sores.

\section{Safety and efficacy test procedure}

A randomized controlled trial was conducted to test the safety and efficacy of the lotion formulations (formulas A and B). There were five treatment groups, with 22 volunteers in each group: Negative control, neutral control, positive control lotion containing 1\% chamomile extract, formula A lotion, and formula B lotion. A Mexameter ${ }^{\circledR} 18$ was used to measure skin erythema [15]. The MED readings were taken before and immediately after 30-min exposure to natural sunlight UV radiation [16]. The subjects were assigned to their groups randomly, and the subjects and evaluators did not know which lotion had been applied (double-blind study). The MED readings were taken at 1, 3, and $24 \mathrm{~h}$ after the application of lotion and 30-min exposure to sunlight. The MED values $\left(\mathrm{mJ} / \mathrm{cm}^{2}\right)$ were statistically analyzed to determine the distribution, homogeneity, and differences in the degree of reduction in erythema after $24 \mathrm{~h}$ for each group

\section{RESULTS AND DISCUSSION}

The yield of S. plana in the ethanol fraction obtained was $14.92 \%$. The fraction was a dark green viscous liquid with a distinctive odor. Analysis showed that the fraction had a water content of $19.02 \%$, total ash content of $11.17 \%$, acid-insoluble ash content of $0.06 \%$, ethanolsoluble fraction content of $8.37 \%$, and a water-soluble fraction content of $21.86 \%$. Phytochemical screening of the $S$. plana ethanol fraction showed the presence of flavonoids, steroids/triterpenoids, tannins, and saponins [11-13]

The yield of the ethanol fraction was 9.91\%. The fraction was a brown viscous liquid with a distinctive odor like that of caramel. Analysis showed that the fraction has a water content of $20.88 \%$, total ash content of $10.94 \%$, acid-insoluble ash content of $0.11 \%$, ethanol-soluble fraction content of $11.37 \%$, and a water-soluble fraction content of $18.86 \%$. Phytochemical screening of the L. siceraria ethanol fraction showed the presence of sterols, saponins, and amino acids.

\section{Determination of flavonoids}

The total flavonoid equivalent to quercetin was $24.995 \%$. The yield of the ethanol fraction was $9.91 \%$. The fraction was a brown viscous liquid with a distinctive odor like that of caramel. Analysis showed that the faction had a water content of $20.88 \%$, total ash content of $10.94 \%$, acid-insoluble ash content of $0.11 \%$, ethanol-soluble fraction content of $11.37 \%$, and a water-soluble fraction content of $18.86 \%$. Phytochemical screening of the L. siceraria ethanol fraction showed the presence of sterols, saponins, and amino acids.

\section{Determination of amino acids}

The HPLC analysis of the ethanol fraction of $L$. siceraria showed the presence of 15 essential amino acids. The level of amino acid equivalent to L-glycine was $0.124 \%$.

\section{Evaluation of lotion formulas $A$ and $B$}

The $\mathrm{pH}$ of formulas $\mathrm{A}$ and $\mathrm{B}$ ranged from 6.18 to 6.39 , which fell within the intended $\mathrm{pH}$ range of $4.5-6.5$.

Viscosity tests using spindle 4 showed that the viscosities of formula $\mathrm{A}$ and B were $4600 \mathrm{cps}$ and $5100 \mathrm{cps}$, respectively. Rheograms of formulas $A$ and $B$ showed that the lotions exhibited thixotropic plastic properties.

\section{Physical stability of lotion formulas}

Organoleptic testing of formulas A and B was performed at $4{ }^{\circ} \mathrm{C} \pm 2^{\circ} \mathrm{C}$, $28^{\circ} \mathrm{C} \pm 2^{\circ} \mathrm{C}$, and $40^{\circ} \mathrm{C} \pm 2^{\circ} \mathrm{C}$. After a cycling test and centrifugation, the lotion formulas did not change color or show clumping or phase separation, which indicated that the lotions had good stability. 


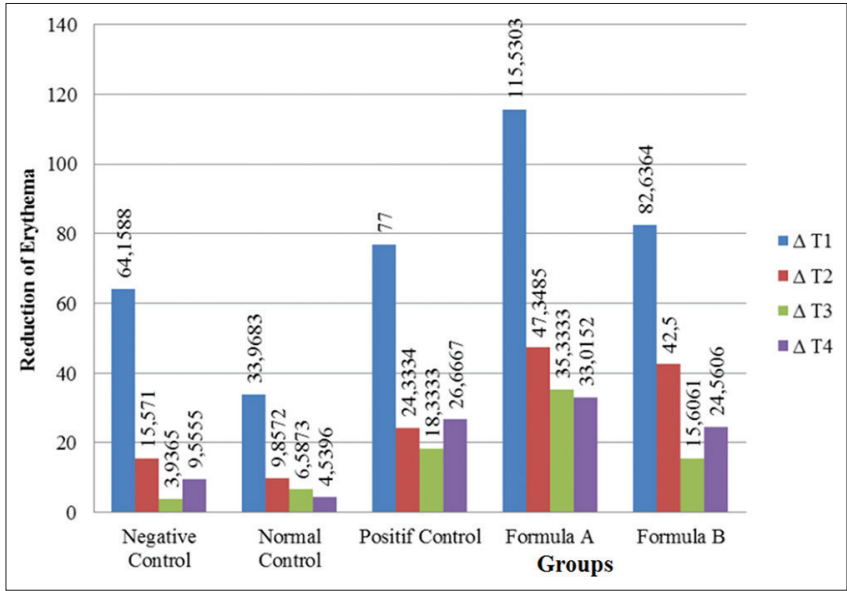

Fig. 1: Reduction of erythema in all groups

\section{Preliminary safety}

A safety test in 12 volunteers as preparation for 48 -h usage did not cause red skin, itching, burning, heat edema, or raised areas.

\section{Efficacy}

The analysis of erythema using one-way ANOVA showed that the formula A group had the highest degree of reduction in erythema among all groups as shown in Fig. 1. The most important therapeutic effect on the reduction of inflammation is the inhibition of the oxidation of arachidonic acid, which leads to the inhibition of lipoxygenase and/ or prostaglandin synthesis activity. Therefore, S. plana may reduce prostaglandin synthesis caused by exposure to the sun.

\section{CONCLUSION}

Among the five groups (positive, negative and neutral control groups, and formula A and B groups), the formula A group, which was treated with formula A containing a $1 \%$ ethanol fraction of S. plana and a $0.5 \%$ ethanol fraction of L. siceraria (Molina) Standl., showed the greatest reduction in the level of erythema $(\mathrm{p}<0.05)$. S. plana may reduce the prostaglandin synthesis caused by sun exposure.

\section{REFERENCES}

1. Han A, Maibach HI. Management of acute sunburn. Am J Clin Dermatol 2004;5:39-47.

2. D'Orazio J, Jarrett S, Amaro-Ortiz AA, Scott T. UV radiation and the skin. Int J Mol Sci 2013;14:12222-48.

3. Lopes DM, McMahon SB. Ultraviolet radiation on the skin: A Painful experience? CNS Neurosci Ther 2016;22:118-26.

4. Diffey BL. Sources and measurement of ultraviolet radiation. Methods 2002;28:4-13.

5. Schwarz T. Mechanisms of UV-induced immunosuppression. Keio J Med 2005;54:165-71.

6. Tabassum N, Hamdani M. Plants used to treat skin diseases. Pharmacogn Rev 2014;8:52-60

7. Shweta K, Swarnlata S. Formulation and evaluation of moisturizer containing herbal extracts for the management of dry skin. Phcog Net 2010;2:409-18.

8. Puvabanditsin P, Vongtongsri R. Efficacy of Aloe vera cream in prevention and treatment of sunburn and suntan. J Med Assoc Thai 2005;88 Suppl 4:S173-6.

9. Tadokoro T, Yamaguchi Y, Batzer J, Coelho SG, Zmudzka BZ, Miller SA, et al. Mechanisms of skin tanning in different racial/ ethnic groups in response to ultraviolet radiation. J Invest Dermatol 2005; $124: 1326-32$

10. Brenner M, Hearing VJ. The protective role of melanin against UV damage in human skin. Photochem Photobiol 2008;84:539-49.

11. Shah BN, Seth AK. Pharmacognostic studies of the Lagenaria siceraria (MOLINA) standley. Int J Pharm Tech Res 2010;2:121-4.

12. Prajapati RP, Kalaria MV, Karkare VP, Parmar SK, Sheth NR. Effect of methanolic extract of Lagenaria siceraria (Molina) standley fruits on marble-burying behavior in mice: Implications for obsessivecompulsive disorder. Pharmacognosy Res 2011;3:62-6.

13. Mashilo J, Shimelis H, Odindo A. Phenotypic and genotypic characterization of bottle gourd [Lagenaria siceraria (Molina) Stabdl.] and implications for breeding: A review. Sci Horticult 2017;222:136-44.

14. Pourmorad F, Hosseinimehr SJ, Shahabimajd N. Antioxidant activity, phenol and flavonoid contents of some selected Iranian medicinal plants. Afr J Biotechnol 2006;5:1142-5.

15. Reuter J, Jocher A, Stump J, Grossjohann B, Franke G, Schempp CM, et al. Investigation of the anti-inflammatory potential of Aloe vera gel (97.5\%) in the ultraviolet erythema test. Skin Pharmacol Physiol 2008;21:106-10.

16. Sayre RM, Agin PP, LeVee GJ, Marlowe E. A comparison of in vivo and in vitro testing of sunscreening formulas. Photochem Photobiol 1979;29:559-66 